\title{
Yeşil Sukuk ve Türkiye’de Uygulanabilirliği
}

\author{
Mehmet ELA*
}

\begin{abstract}
$\ddot{O} Z$
Yeşil sukuk henüz niş bir enstrüman olarak son yıllarda dikkatleri üzerine çekmiştir. Özellikle son birkaç yılda yeşil sukuk ihraçları artmaya başlamıştır. Yeşil sukukun ihraç edilmesinin temelinde sunduğu birçok avantaj yatmaktadır. Yeşil sukukun avantajlarını fark eden birçok ülke yeşil sukuka yönelik yasal ve vergisel düzenlemelere gitmiştir. Türkiye'de yeşil sukuk ihracı ile fonlanabilecek birçok yeşil proje bulunmasına răgmen yeşil sukuka ilişkin yasal ve vergisel düzenlemeler henüz gündemde değildir. Bu durum Türkiye’de önemli bir problem teşkil etmektedir. $\mathrm{Bu}$ noktadan hareketle ele alınan çalışmanın amacı yeşil sukukun Türkiye'deki potansiyeline araştırmak ve atılması gereken adımlara yer vermektir. Bu amaca ulaşmak için çalışmada betimleyici bir dil kullanılarak dünyada yeşil sukuk piyasasına iliş̧kin genel bilgilere yer verilmiştir.
\end{abstract}

Anahtar Kelimeler: Sukuk, Yeşil Sukuk, Türkiye.

JEL Sinıflandirması: D53, G12, Q50.

\section{Green Sukuk And Its Applicability in Turkey}

\begin{abstract}
As a niche instrument, green sukuk has attracted attention in recent years. Especially in the last few years, green sukuk issuances have begun to increase. There are many advantages laid on the basis of issuing green sukuk. Many countries that have recognized the benefits of green sukuk have made legal and tax arrangements for green sukuk. Although Turkey has many green projects that could be funded through the green sukuk issuance, legal and tax regulations on green sukuk are not on the agenda yet. This situation poses a significant problem in Turkey. From this point of view, the aim of this study is to investigate the potential of green sukuk in Turkey and emphasize the steps to be taken. In order to achieve this aim, in the study, general information about the green sukuk market in the world is given in a descriptive language
\end{abstract}

Key Words: Sukuk, Green Sukuk, Turkey.

JEL Classification: D53, G12, Q50.

\section{GİRIŞ}

Yeşil çevre politikaları son zamanlarda birçok ülkenin dikkatini çekmeye devam etmektedir. $\mathrm{Bu}$ açıdan birçok ülke çevreye duyarlı yenilenebilir enerji yatırımlarına hız vermektedir. Artan çevreye duyarlı yatırımları finanse etmek adına ise ilk olarak 2008'de Dünya Bankası'nca yeşil tahviller ihraç edilmiş ve daha sonra bu süreç diğer ülke ve kuruluşların yeşil tahvil ihracı ile devam etmiştir. Yeşil tahvilin oluşturduğu altyapı ve tecrübeden istifade eden yeşil sukuk konusunda ise çalışmalar 2012 yılında başlamış olup ilk yeşil sukuk ihracı Tadau Energy tarafindan 2017 yllında gerçekleştirilmiştir.

Yeşil sukukun ihraç edilme nedenleri arasında hiç şüphesiz yeşil sukukun birçok avantajının var olması sayılabilmektedir. Oldukça geniş bir yatırımcı

\footnotetext{
* Dr. Öğr. Üyesi, Osmaniye Korkut Ata Üniversitesi, İktisadi ve İdari Bilimler Fakültesi, Maliye Bölümü. mehmetela@osmaniye.edu.tr
} 
tabanına sahip olan yeşil sukuk, gerek İslami yatırımcılara ve gerekse de çevreye duyarlı geleneksel yatırımcılara hitap edebilmektedir. Diğer yandan sukukla benzer risk ve getiriye sahip olan yeşil sukuk rekabetçi fiyatlandırmaya da sahiptir. Yeşil sukuk finansmanda çeşitlendirme sağlayarak gerek özel sektöre ve gerekse de ülkelere yeşil projeler için önemli bir finansman kaynağı da sunmaktadir.

Dünyada birçok ülke ve bölge yeşil sukukun avantajlarını fark etmiş ve buna yönelik olarak çeşitli yasal ve vergisel düzenlemelere gitmiştir. Türkiye'de ise yeşil sukuk konusunda henüz herhangi bir yasal ve vergisel düzenleme olmamakla birlikte Türkiye'de genel olarak sukuk konusundaki düzenlemeler eksik ve yetersizdir. Diğer yandan Türkiye'de yeşil sukuk konusunda herhangi bir akademik çalışma da bulunmamaktadır.

Yeşil sukukun Türkiye için avantajları ve potansiyeline değinen bu çalışma yeşil sukuk konusundaki bilgi açığını kapatmak üzere kaleme alınmıştır. $\mathrm{Bu}$ amaçla çalışma 9 başlıktan oluşturulmuştur. Birinci başlıkta yeşil sukuk tanımlanmış ve özellikleri belirtilmiş, ikinci başlıkta yeşil sukukun yapısı ve aşamaları incelenmiş, üçüncü başlıkta yeşil sukukun çeşitli finansman yöntemlerine uygunluğu irdelenmiş, dördüncü başlıkta yatırımcı tabanı işlenmiş, beşinci başlıkta yeşil sukuk alanındaki gelişmelere değinilmiş, altıncı başlıkta yeşil sukukun faydaları işlenmiş, yedinci başlıkta yeşil sukukun problemleri incelenmiş ve çözüm önerileri sunulmuş, sekizinci başlıkta yeşil sukukun geleceğine ilişkin öngörülerde bulunulmuş ve dokuzuncu başlıkta Türkiye'de yeşil sukukun uygulanma potansiyeli araştırılmıştır.

\section{YEŞIL SUKUKUN TANIMI VE ÖZELLIKLERI}

Yeşil sukuk bir yandan çevresel amaçlara hizmet ettiğinden ve bir yandan da Şeriat'a uyumluluk gösterdiğinden oldukça geniş kapsamlı bir yatırım alanını kapsamaktadır. Bu anlamda yeşil sukuk tanımlanırken bu iki husus yani çevreye duyarlılık ve Şeriat'a uyumluluk vurgulanmakta, bir arada ele alınmaktadır. Bu bağlamda, Climate Bonds (2017)'a göre yeşil sukuk, yenilenebilir enerji ve diğer çevresel varlıklara yönelik olan ve Şeriat ile uyumlu yatırımlardır. Alam vd. (2016:167)'ya göre yeşil sukuk, güneş enerjisi parkları, biyogaz tesisleri ve rüzgar çiftlikleri gibi çevre dostu projeleri finanse eden Şeriat'a uygun yatırım araçlarıdır. Kidney (2015)'e göre ise yeşil sukuk, fonları yeşil projelerde kullanılan sabit getirili İslami enstrümanlardır. Zain vd. (2017)'ye göre yeşil sukuk, iklim değişimi konularını ve çevreyi korumayı amaçlayan varlıklardan oluşan bir havuzun dayanak varlık olduğu inovatif ve Şeriat'a uygun menkul kıymetler olarak tanımlanmaktadır. Bazı tanımlamalar ise yeşil sukukun sadece çevre dostu yönünü ele almış, bu anlamda yeşil sukukun ayırıcı özelliklerinden olan Şeriat'a uyumluluğu göz ardı etmiştir. Bu bağlamda, PWC (2016:167)'ye göre yeşil sukuk, yeşil proje ve varlıkları fonlamaya yarayan bir sukuk çeşididir. Ali ve Abdullah (2017)'ye göre ise yeşil sukuk yenilenebilir enerji ve diğer çevresel varlıklara yönelik yatırımı ifade etmektedir.

Yeşil sukuk kavramı finansal piyasalarda dikkatleri üzerine çekmeye başlamıştır. Yeşil tahvile benzer şekilde yeşil sukuk ihracından elde edilen fonlar, 
çevresel ve doğal kaynakların korunmasında ve enerjinin korunması ve yenilenmesinde kullanılmaktadır. Doğası itibariyle varlığa dayalı ve reel ekonomi ile bağlantılı olan sukuk, finansal getiriler ve sosyal yararı maksimize etmeye çalışan sosyal yönden sorumlu finansla da benzer özellikler taşımaktadır (G20 Green Finance Study Group, 2016:20).

Yeşil sukuk çeşitli amaçlarla geliştirilmiş finansal bir üründür. Bu amaçla yeşil sukuk şu amaçlarla geliştirilmiştir (Alam vd., 2016:167; Abdul Aziz, 2017b; Zain vd., 2017:10): (i) Çevrenin korunması ve Şeriat'ın çevreyi korumak ile ilgili gerekliliklerinin karşılanması (ii) İklim değişimleri ile mücadele edilmesi, (iii) Sürdürülebilir kalkınma ve çevre ile ilgili yatırımların finanse edilmesi, (iv) Yeşil projelerin fonlanmasında artış için İslami finansal inovasyonların desteklenmesi.

Yeşil sukukun kullanıldığı yeşil projeler ve bu anlamda dayanak varlıklar arasında temiz enerji, toplu taşımacılık, su koruma, ormancılık ve düşük karbonlu teknolojiler yer almaktadır. $\mathrm{Bu}$ yeşil finansman girişimleri aynı zamanda insanların ve toplumların yaşamlarını iyileştirmek için tasarlanan sosyal sorumluluk yatırımlarını da içermektedir (Khazzam, 2015). Diğer yandan yeşil sukukun kullanılabileceği uygun varlıklar arasında şunlar sayılabilmektedir (Climate Bonds, 2017):

- Güneş parkları

- Biyogaz tesisleri

- Rüzgâr enerjisi

- Enerji verimliliği

- Yenilenebilir iletim ve altyap1

- Elektrikli taşıtlar ve altyapı, hafif raylı sistemler

- Veya bir devlet yeşil ödeme / sübvansiyonunu finanse edebilir.

Yeşil sukuk birtakım özellikleri bünyesinde barındırmaktadır. $\mathrm{Bu}$ özelliklerden bazıları şöyledir (World Bank, 2017; Chew, 2014; Ali ve Abdullah, 2017):

- Yeşil sukuk ihracindan elde edilen getiriler sadece çevre dostu yatırımlarda kullanılmalıdır. Bu anlamda yeşil sukuk ihracından elde edilen fonlar doğayı ve doğal kaynakları koruma, enerjiyi muhafaza etme, yenilenebilir enerji üretimini arttırma ve sera gazları emisyonunu azaltma amaciyla kullanılabilmektedir.

- İhraçtan önce sukukun yeşil olduğunun açıklanması gerekmektedir. Diğer yandan, sukuk fonlarının kullanımı hakkında yeterli şeffaflı̆̆a sahip olunmas1 ve raporlama yapılmas1 gerekmektedir.

- Yeşil sukuk, geleneksel finans ile İslami finans arasındaki boşluğu kapatmak için iyi bir adım ve şanstır. Nitekim yeşil sukuk gerek çevresel öncelikleri olan geleneksel yatırımcıya ve gerekse de Şeri duyarlılıkları olan İslami yatırımcıya hitap edebilmektedir. Bu anlamda yeşil sukuk, yatırımcı tabanı ve fonlarda çeşitlendirmeyi de desteklemektedir. Ayrıca İslami finans için yeni bir varlık sınıfını oluşturması da olumlu bir adımdır.

- Yeni bir ürün olarak tüm dünyada kullanılabilir yapıdadır. 
-Yeşil sukuk tüm geleneksel ve yeşil yatırımcılara açiktır. Şeriata uygun veya da çevre dostu yatırım yapmak isteyen yatırımcılar için oldukça uygundur.

-Yükselen piyasa ekonomileri ve gelişmekte olan ülkelerin altyap1 yatırımlarında kullanılabilir.

- Yeşil sukuk yatırımcılara, verdikleri paranın sadece yeşil projelerde kullanılacağı yönünde güvence verir. Toplanan fonlar başka bir amaç için kullanilamaz.

\section{YEŞIL SUKUKUN YAPISI VE ASAMALARI}

Yeşil sukuk yapısı, korumalı ve belirli amaca sahip (ring fenced) projelerden veya da belirli niteliklere sahip varlıklardan elde edilen gelecekteki nakit akımlarının (getirilerin) menkul kıymetleştirilmesi ile elde edilmektedir. Sukuk ihracindan elde edilen fonlar genelde yeşil ve Şeriat'a uygun projeler için kullanılmaktadır. SPV'nin giderlerini düştükten sonra elde kalan getiriler sukuk yatırımcılarına ödenmektedir. Kaynak kuruluş varlığı vadede SPV'den almayı taahhüt etmektedir. Satın alma fiyatı, sukukların toplam nominal değeri ve arta kalan ödenmemiş periyodik karlardan oluşmaktadır (Alam vd., 2016:174). Bu anlamda yeşil sukukun yapısı ve aşamalarına ilişkin bilgiler Şekil 1'de verilmiştir.

Şekil 1. Yeşil Sukukun Yapısı ve Aşamaları

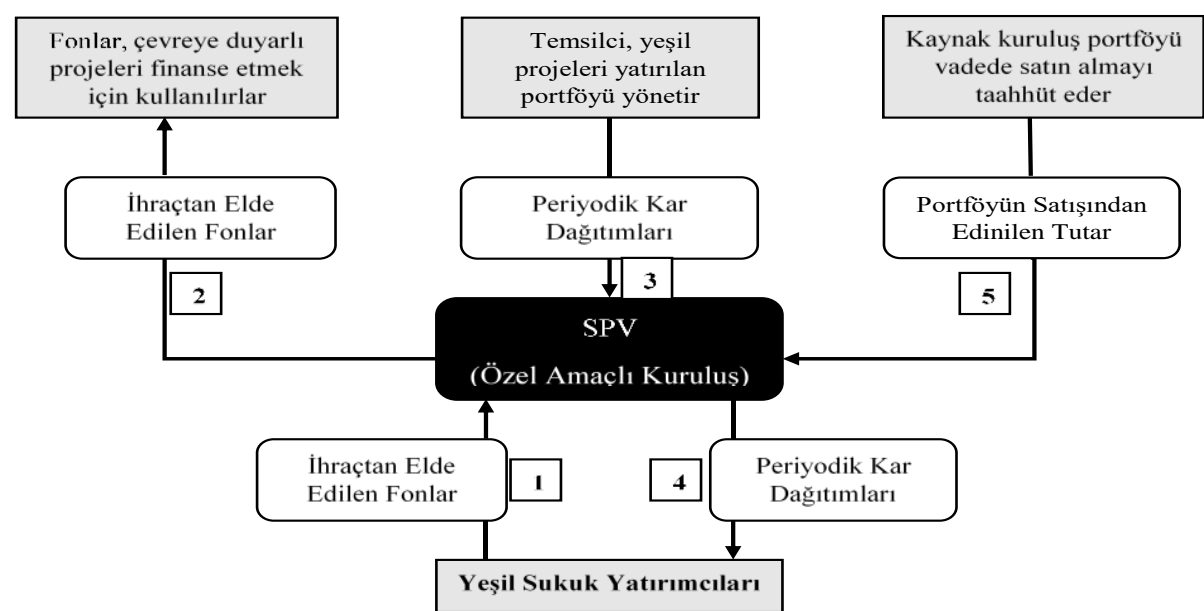

Kaynak: Alam, N., Duygun, M. and Turk Ariss, R. (2016). Green Sukuk: An Innovation in Islamic Capital Markets ( Edited by Andre Dorsman, Özgür Arslan-Ayaydın and Mehmet Baha Karan). Energy and Finance Sustainability in the Energy Industry (First Edition). Switzerland: Springer International Publishing, p. 175.

\section{UYGUNLUĞU \\ III. YEŞiL SUKUKUN ÇEŞITLİ FİNANSMAN YÖNTEMLERINE}

Yeşil sukuk, sukukun bir çeşidi olarak bazı İslami finansman türlerine dayanmak zorundadır. Şöyle ki, sukuk yapılandırılırken bazı İslami finansman yöntemlerine göre aşamalar gerçekleşmekte ve sukuk dayandığı finansman çeşidinin adını almaktadır (ijara sukuk, istisna sukuk gibi). Yeşil sukuk da benzer şekilde birtakım İslami finansman türlerine (ijara, muşaraka gibi) veya da birkaç finansman türüne göre birlikte (hibrid biçimde; birkaç finansman türünün bileşimi) yapılandırılabilmektedir. Bu açıdan aşağıda yeşil sukukun çeşitli 
finansman yöntemlerine uygunluğuna ilişkin açılamalara yer verilmiştir (PWC, 2016: 174-175):

\section{A. İstisna}

İstisna, anlaşma yapıldığ 1 anda var olmayan üretilecek varlıklar için yapılmaktadır. İstisna ile bir taraf belirli şartlara ve özelliklere haiz bir varlığı anlaşılan fiyattan ve anlaşılan vadede üretmeyi vaat etmektedir. Bu üretilecek şey bir emtia veya binalar, fabrikalar, uçak ya da gemi gibi bir varlık olabilmektedir. $\mathrm{Bu}$ nedenle güneş veya rüzgar çiftlikleri gibi yenilenebilir enerji varlıklarının yapımında da kullanılabilir. İstisna yapım (inşa) ve sermaye harcaması için kullanılabilmektedir. İstisna sonucunda üretilen varlığın fiyatı da taraflarca belirlenen bir vadeden önce veya sonra da taksitler halinde ödenebilmektedir. İstisna geniş ölçüde denenmiş ve test edilmiştir bu nedenle de dokümantasyonunda Şeriat alimleri ve kurullarınca bir fikir birliği olduğundan dolayı genel olarak standartlaşma vardır. Ancak yine de varlık ve üretimi kapsamında bazı karışıklıklar çıkabilmektedir.

\section{B. İjara}

İjara en çok kullanılan sukuk türlerinden birisidir ve arazi ya da işyeri gibi ancak var olan bir maddi varlık için kullanılabilmektedir. Bu da ijarayı, yapım bittikten sonra işletim aşamasında yenilenebilir enerji altyapıları için kullanılabilir kılmaktadır. Dayanak yeşil varlık havuzu en az sukuk ihraç tutarı miktarında piyasa değerine sahip olan varlıklardan oluşmalıdır. İjara SPV'nin sukuk ihraççısından (kaynak kuruluştan) varlıkları örneğin güneş santralini satın aldığı bir sat-geri al modeline dayanmaktadır. Yatırımcılar yeşil varlıkları satın almakta ve daha sonra onları ihraççıya belirli bir kira (getiri) karşılığında tekrar kiralamaktadır.

İjara standart bir dokümantasyona sahiptir ve Şeriat'a uygunluğu konusunda fikir birliği vardır.

\section{Muşaraka}

Muşaraka maddi duran varlıklarda ortaklığa imkan tanımaktadır. Varlık havuzu var olan varlıklar veya varlık havuzu kriterine uygun olan ve sukuktan elde edilen fonlarla satın alınan yeni varlıklardan oluşabilmektedir. İstisna ve ijaranın temel farklarına göre istisnada sermaye ortaklığ 1 olduğundan dolay1 yatırımcılar zararın da belirli oranına katlanmak zorundadır. Sukukta ihraççı kuruluşa değil de varlıklar üzerinde sahiplik payı bulunsa da bu durumda muşaraka tahvilden çok geleneksel hisse senedine yakın olmaktadır.

Yeşil muşaraka sukuk bu nedenle yüksek risk-getiri tercihi olan yatırımcılara bir olanak sunmaktadır. Riske maruziyet yenilenebilir enerji projesinin hangi aşamasının finanse edildiğine bağlı olarak değişmektedir: İnşaat (kurulum) aşamasında risk daha yüksek iken işletim aşamasında risk düşüktür. Kar paylaşımı ise zarar paylaşım oranından farklı olarak taraflarca belirlenen bir oranda olabilmektedir. SPV kurularak kendi, payını borçluya (kaynak kuruluşa) kiralamaktadır. Sukuk yatırımcılarının getirisi periyodik kira ödemeleri ile yapilmaktadır. 


\section{YEŞiL SUKUKUN YATIRIMCI TABANI}

Sukukun yatırımcı tabanı hem genel olarak sukukun yatırımcı tabanından hem de geleneksel tahvillerin yatırımcı tabanından oldukça geniştir. Şöyle ki, Sukukun çevresel konuları da içermesi ile yeşil sukuk ihraçları İslami finansman ürünlerine halihazırda ilgi gösteren geleneksel yatırımcıları kendine çekebilecekken İslami yatırımcılara da daha geniş yelpazede bir ürün çeşidi sunmaktadır (Irvine vd., 2014:29). Bu anlamda sukuk yatırımcıları başta İslami yatırımcilar olmak üzere bir miktar da geleneksel yatırımcıyı kendine çekebilirken, yeşil tahviller genel olarak geleneksel yatırımcı tabanından yararlanmaktadır. Yeşil tahvilin ve sukukun yatırımcı tabanını birleştiren yeşil sukuk, hem sukuk yatırımcılarına ve hem de geleneksel çevre odaklı yatırımcılara hitap etmektedir (Mohammed, 2014). Bu durum Tablo 1'de de kisaca özetlenmiștir.

Tablo 1. Yeşil Sukukun Yatırımcı Tabanı

\begin{tabular}{|l|l|l|}
\hline & Yeşil Olmayan & Yeşil \\
\hline Tahvil & Geleneksel yatırımcılar & $\begin{array}{l}\text { Geleneksel yatırımcılar + Geleneksel } \\
\text { yeşil yatırımcılar }\end{array}$ \\
\hline Sukuk & Geleneksel yatırımcılar + İslami yatırımcılar & Tüm yatırımcılar \\
\hline
\end{tabular}

Kaynak: Abdul Aziz, A. H. (2017a). Green Bond/Sukuk. https://www.rbf.gov.fj/getattachment/LeftMenu/Financial-Inclusion/Events/Workshop-on-Sustainable-Finance-Initiatives/Session-4-Green-Bonds-byAhmad-Hafiz-Abdul-Aziz-World-Bank-Group.pdf?lang=en-US (Erişim Tarihi:05.06.2018).

Yeşil sukukun geniş yelpazeli bir yatırımcı tabanına hitap etmesine örnek olarak Endonezya tarafindan ihraç edilen yeşil sukuk verilebilmektedir. Şubat 2018'de Endonezya 2.25 milyar dolar tutarında 5 yıl vadeli yeşil sukuk ihraç etmiştir. İslami yatırımcılar bu sukukun \%32'sini alırken \%33'lük pay Avrupa ve ABD'li yatırımcılarca satın alınmıştır (Vizcaino, 2018). Bu durum da göstermektedir ki, yeşil sukuk finansman kaynaklarında çeşitlendirme sağlama ve borç kırılganlığ gibi problemleri azaltmada önemli bir enstrüman haline gelirken diğer yandan ülkelerin yeşil yatırımlarını finanse etmede de önemli rol oynamaktadır.

\section{YEŞIL SUKUK ALANINDAKİ GELIŞMELER}

Geleneksel sermaye piyasalarında, çevre odaklı tahviller son yıllarda ortaya çıkmaya başlamıştır. Örneğin Dünya Bankası, 2008 yılından beri 'Dünya Bankası Yeşil Tahvilleri' adı verilen bir tahvil türü ihraç etmektedir. Dünya Bankası'nın tüm faaliyetlerini finanse etmek yerine, Dünya Bankası Yeşil Tahvillerinden elde edilen gelirler, düşük karbonlu kalkınma için önceden belirlenmiş ölçütleri karşılayan bazı projelere destek vermek amaciyla ihraç edilmektedir. $\mathrm{Bu}$ tahviller, çevreye duyarlı yatırımcılar tarafından çok iyi karşılandı ve bu yapı, diğer uluslar üstü, kurumsal ve devlet kuruluşlarından oluşan ihraççılar için bir model haline gelmiştir (Mohammed, 2014). Dünya Bankası'nca oluşturulan modelin çeşitli özel sektör kuruluşlarınca benimsenmesi sonucu yeşil tahvil ihraçları artmış ve günümüzde piyasa 80 milyar dolarlık bir hacme ulaşmıştır (Hirtenstein, 2015).

Yeşil tahvilin oluşturduğu tecrübeden yararlanan yeşil sukuka ilişkin çalışmalar ancak 2012'de başlamıştır. Bu anlamda yeşil tahvil kavramına olanak tanımak adına Yeşil Sukuk Çalışma Grubu 2012'de İklim Tahvili Girişimi 
(Climate Bonds Initiative - CBI), Orta Doğu ve Kuzey Afrika Temiz Enerji İşletme Konseyi (CEBC) (Clean Energy Business Council of the Middle East and North Africa) ve Körfez Tahvil ve Sukuk Kurumu (Gulf Bond and Sukuk Association) tarafindan kurulmuştur. Bu grubun görevi, potansiyel yatırımcılar için Şeriata uyumlu kategorisine giren yeşil enerji projelerini belirlemektir. 2012'nin sonunda 2 Avustralyalı güneş enerjisi şirketi olan Solar Guys International ve Mitabu Australia, Malezya'da yapılandırılan yeşil sukuk ihracı ile 50 megawattlık fotovoltaik (güneş enerjisinin enerjiye çevrilmesi) projeyi ilan etmişlerdir (Alam vd., 2016:175). Ancak yeşil sukuk ihracı güneş enerjisi projesi ile ilgili planlama sorunları nedeniyle ertelemiştir (PWC, 2016:172).

2014'de Malezya Menkul Kiymet Komisyjonu (SC) sukuk rehberini güncellemiş ve SRI (sosyal yönden sorumlu) sukuk ihracı için çeşitli koşullar belirlemiştir. SRI sukuk yeşil sukuku da kapsayacak şekilde düzenlenmiştir. Yeni sukuk rehberine göre SRI sukuk ihracından elde edilen fonlar doğayı ve doğal kaynakları koruma, enerjiyi muhafaza etme, yenilenebilir enerji üretimini arttırma ve sera gazları emisyonunu azaltma amaciyla kullanılabilmektedir. 28 Ağustos 2014'te Malezya SRI Sukuk Yapısı'nı aşağıdaki amaçlara hizmet etmek amacıyla hayata geçirmiştir (Ali ve Abdullah, 2017):

desteklemek

-Sürdürülebilir ve sorumlu yatırım girişimlerinin finanse edilmesini

-Sukuk piyasasına katılımı arttırmak ve bireysel-sofistike yatırımcıların daha geniş yelpazede yatırım ihtiyaçlarına karşılık vermek

-(SRI) ürünlerin yatırımcı ve ihraççıları için ekosistemi desteklemeyi kolaylaştırmak

2014'te Malezyalı ve Birleşik Arap Emirlikleri'nden Dubaili kuruluşlarca yeşil sukukun gelişimine öncülük edilmiştir. Dubai Enerji Yüksek Kurulu (DSCE) ve Dünya Bankası, Dubai'nin yeşil yatırım programı için yeşil tahvil ve sukukların kullanıldığı bir finansman stratejisi oluşturmak adına bir araya gelmişlerdir (Alam vd., 2016:176). Diğer yandan, Ağustos 2015'te Global İklim Değişikliği Üzerine İslami Deklarasyon T(he Islamic Declaration on Global Climate Change) yayınlanmış ve devletleri, özel sektörü, yatırımcıları ve dünyadaki tüm Müslümanları iklim değişikliğine karşı hareket etmeye çağırmıştır. Her yıl yapılan World Islamic Economic Forum, Kasım 2015'te yapılmış ve bir oturumunu Yeşil Teknolojiler için İslami Finans konusuna ayırmıştır. Bu çabaların sonucunda geleneksel piyasalarda etik ve sosyal yönden sorumlu yatırım arayan kesimin ilgisi İslami finansa çekilmiştir (G20 Green Finance Study Group, 2016).

Tüm bu gelişmelerin ardından Temmuz 2017'de Malezya'da Tadau Energy tarafindan 58 milyon dolar tutarında ve 2-16 yıl vadeli ilk yeşil sukuk güneş fotovoltavik kuruluşunun yapımı için ihraç edilmiştir. Yine Malezya'da Quantum Solar Park tarafından 235 milyon dolar tutarında ve 2-18 yıl vadeli yeşil sukuk güneş fotovoltavik kuruluşunun yapımı için ihraç edilmiştir (Abdul Aziz, 2017b). Malezya menşeli Mudajaya Group Berhad (Sinar Kamiri) 2018'de 63 milyon dolarlık ve 18 ay vadeli yeşil sukuk ihraç etmiştir. Bu ihraç 2017 
Temmuz'da Tadau Energy tarafindan ihraç edilen ilk yeşil sukuk ihracından sonraki dördüncü yeşil sukuk ihracıdır. Elde edilen fopnlar güneş fotovoltaik tesisleri kurulumu için harcanmaktadır (Rado, 2018). Şubat 2018'de dünyanın en büyük kömür ihracatçısı olan Endonezya dünyanın devlet tarafından ihraç edilen ilk yeşil sukuk ihracına imza atmıştır. 1.25 milyar dolarlık bu ihracın getirileri aşırı talep nedeniyle 30 baz puan düşmüş ve yüzde 3.75 getiri sunmuştur (Dunkley, 2018).

\section{YEŞIL SUKUKUN FAYDALARI}

Yeşil sukuk, sosyal yönden sorumlu yapısı yanında İslami ve geleneksel piyasaları birleştiren özelliğiyle gerek ihraççı gerekse de yatırımcılara önemli avantajlar sağlamaktadır. Yeşil sukukun söz konusu avantajları şu şekildedir (Alam vd., 2016:176; Abdul Aziz, 2017a; G20 Green Finance Study Group, 2016; PWC, 2016:168-169):

-Yeşil sukuk ilk olarak yeşil olmayan sukuk ile benzer risk ve getiriye sahiptir. İhraççının kredi derecesi sukukun da kredi derecesini belirlediğinden yeşil sukuk diğer sukuk türleri ile aynı risk ve getiriye sahiptir. Yatırımcı ise direkt olarak yeşil proje riskine maruz değildir. Bu özelliği ile yani yatırımcıdan çok ihraççının yeşil yatırım riskini absorbe etmesinden dolayı yeşil sukuk hızlı büyüme potansiyeline sahiptir.

-Yeşil sukuk rekabetçi fiyatlandırmaya sahiptir. Şöyle ki, yeşil sukuk hem İslami hem de geleneksel yatırımcılara hitap ettiğinden dolayı geniş bir yatırımcı tabanı vardır ve bu nedenle rekabetçi fiyatlandırmaya sahiptir. Bu durumda yeşil sukukta verilen getiri geleneksel sukuktan daha düşük olabilmektedir. Örneğin Malezya'da Malezya ringiti bazlı yeşil sukukun getirisi geleneksel tahvilden 5 ila 7 baz puan daha azdır.

-Yeşil sukuk geleneksel finansman ile kapatılamayacak fon açı̆̆ını kapatmada önemli bir potansiyele sahiptir. Yeşil sukukun yatırımcı tabanı geleneksel tahvillerden farklı olduğundan kriz vb. nedenlerle geleneksel piyasalardan elde edilemeyen fonlar yeşil sukuk arzı ile kapatılabilecektir.

-Yeşil sukuk daha geniş yatırımcı havuzuna ulaşmayı sağlamaktadır. Yeşil sukuk iki farklı yatırımcı tabanına hitap etmektedir. İlk olarak, İslami yatırımcı yatırım tercihlerinde Şeriat'ın çevre korunma ile ilgili hükümlerine uyum sağlayabilecek ve bunu yatırım tercihine yansıtabilecektir. İkinci olarak, yeşil sukuk sukuka yatırım yapmayan ancak yeşil güven belgesinden dolayı yatırım yapacak olan İslami olmayan (geleneksel) yatırımcıyı da çekme potansiyeline sahiptir. Yatırım kararlarında çevresel ilgilerini göz önüne alan yatırımcı havuzunun payı son zamanlarda yatırım piyasasının geniş bir bölümünü kapsamaktadır. Örneğin, Eylül 2014'te 24 trilyon dolarlık varlık yönetimini temsil eden yatırımc koalisyonu -Global Investor Council on Climate Change, PRI ve UNEP Finance Initiative tarafından oluşturulmuştur- çevreye ve iklimi koruyan projelere yatırım yapma isteklerini dile getirmişler ve devletleri iklim problemlerine yönelik çözümlere olan yatırımları desteklemeye davet etmişlerdir.

-Yeşil sukuktan elde edilen fonlar sadece yeşil projelerde kullanılabileceğinden yeşil sukuk yatırımcılara yeşil güven belgeleri sunmak 
zorundadır. Yeşil güven belgeleri ise sukuk ihraç eden kuruluştan değil finanse edilen varlıktan kaynaklanmaktadır. Bu da yeşil varlık havuzuna sahip herhangi bir kuruluşun yeşil güven belgesine (yani kuruluşun yeşil projeler yapan bir kuruluş veya da yeşil kuruluş olduğunu gösterir belge) sahip olmas1 gerekmeksizin sukuk ihraç edebileceği anlamına gelmektedir. Bu durum potansiyel ihraççı havuzunu genişletmektedir ki bu da düşük karbonlu ekonomiye daha hızlı geçişi sağlamaktadır. Örneğin, bir petrol şirketi fonların şirketin yeşil projelerinde kullanılacağı yönündeki güvencesi ile yeşil sukuk ihraç ederek elde edilen fonları güneş enerjisi yatırımında kullanabilmektedir.

-İslam dini, çevrenin korunmasına önem vermektedir. Bu anlamda İslam öğretileri temel olarak doğal kaynakların korunmasını ve tüm canlılara sayg1 duyulmasını teşvik etmektedir. Yeşil sukuk ise İslam'ın çevrenin korunması ile ilgili öğretilerine uyum gösterirken diğer yandan yatırım tercihlerinde çevrenin korunması gibi Şeri ihtiyaçları karşılamaktadır.

-Son olarak, yeşil sukuk sermaye piyasasında ticareti yapılabilen (işlem görebilen) bir enstrümandır ve bu nedenle de yeşil sukukun transferi ve satış potansiyeli vardır. Yeşil sukukun sağladığı diğer bir fayda da yeşil güven belgelerinin yatırımcılara ve paydaşlara pazarlanabilmesidir.

VII. YEŞIL SUKUKUN PROBLEMLERİ VE ÇÖZÜM ÖNERILERI

Yeşil sukuk niş bir enstrüman olduğundan dolayı yeşil sukuk piyasası henüz gelişim aşamasındandır ve bu nedenle de yeşil sukuk birtakım problemlere sahiptir. Bu problemler şu şekildedir (Al Natoor, 2017; MIFC [Malaysia International Islamic Financial Centre], 2016:4):

-ìlk problem sukuk uygulamalarında standartlaşmanın olmaması ve yasal problemlerdir. Nitekim, en azından standart bir yapı kurulana değin devletler, yatırımcılar ve Şeriat kurulları için kabul edilebilir olan yeşil sukuk yapıları ve çerçevelerini tasarlamada harcanan zaman, uzun ve maliyetli olabilmektedir. Buna rağmen, sektör hızla değişen düzenleyici ortama ayak uydurmak ve en azından yerel bir standardizasyona ulaşmak için şimdiden mücadele etmektedir. Ancak, piyasanın yeni oluşan (niş) yapısını yansıtır biçimde yeşil sukuk için piyasa norm ve standartları hala gelişim aşamasındadır. Çeşitli rehberler olmasına rağmen piyasa hala kendi kendini düzenler haldedir. $\mathrm{Bu}$ rehberler arasında fonların (sukuk ihracından) kullanımı, proje değerlendirme süreci ve proje seçimi, fonların yönetimi ve raporlama hakkında bir grup banka tarafından 2014 yılında yayinlanan International Capital Market Association's Green Bond Principles sayılabilmektedir. Diğer yandan belirli sektörlere eğilen Climate Bond Inıtiative de önemli rehberlik hizmeti sunmaktadır.

-Uygulamada ve belgelemede yaşanan standartlaşma sorunu performans ölçümü için de kendini göstermektedir. Nitekim, yeşil sukukun performans ölçümü için gerekli standart ve onay sistemi henüz yoktur.

- Üçüncü olarak yeşil sukuk yüksek risk profiline sahip olabilmektedir. Çünkü, birçok çevre dostu proje, yeşil teknolojilerin yapım ve işletiminden dolayı birçok sofistike yeni teknoloji içermektedir. 
-Dördüncü olarak yatırımcıların sukuk fonlarının ekonomik değeri olan ve kabul edilebilir ve belirli yeşil standartları karşılayan projelere yatırılacağ 1 yönünde ikna edilmesi oldukça zordur. Çünkü bu yatırımcılar için hem sukukun karmaşıklığı hem de yeşil projeler için sukuk ihracında gerekli çeşitli yeşil standartları karşılamak oldukça girift bir hal almaktadır.

-Son olarak, yeşil sukukun ikincil piyasası oldukça küçüktür. Bunun temel nedeni sukuku elinde tutan yatırımcıların az sayıda olması ve diğer kurumsal yatırımcıların, yatırımcıların likidite beklentilerini karşılayabilecek yeterli ikincil piyasa beklentisidir.

Yeşil sukukun gelecekteki gelişimini temin etmek ve problemlere çözüm üretmek adına birtakım öneriler sunulabilmektedir. $\mathrm{Bu}$ çözüm önerileri şu şekildedir (PWC, 2016:176-177).

Yeşil Sukuk İçin Standartlar Oluşturma:

Yatırımcılar yatırım yaptıkları yeşil sukukun çevresel etkilerini görmek isteyeceklerinden yeşil sukuk piyasası için güçlü yeşil güven belgelerinin oluşturulması gerekmektedir. Bu açıdan münferit ihraçlarda bir miktar da olsa çevresel amacın olması gerekmektedir. İklim üzerine eğilen ve yeşilin ne olduğu konusunda açıklama ve kurallar getiren açık rehberlerin olması yeşil sukuk piyasasının temelini oluşturmaktadır.

Yeşil tahvil piyasası için gerekli yeşil standartlar nitekim yeşil sukuk ihraçlarına da uygulanabilir. Bu zamana değin sadece Climate Bonds Standards and Certification tasarısı, hangi varlıkların yeşil olduğu sorusuna bilimsel bir standart ve açıklama getirmiştir.

Varlıkların yeşil güvenirliğinin sağlanması için standart oluşturma süreci yeşil tahvilinkinden daha kolay olabilmektedir. Nitekim, Şeriata uyumlu bir varlık havuzu sağlamak için sukuk piyasasında halihazırda kurulmuş olan süreçler üzerine inşa edilebilir. Sukuk zaten Şeriat'a uygunluk konusunda şeffaflı̆̆ sağlamak üzere çeşitli süreçler içermektedir. Şeriata uygunluk ve yeşile uygunluk konusundaki süreçler nitekim benzer olabilmektedir. Çünkü her iki süreç te finansal olmayan bir kriteri ihraç sürecine dahil etmektedir.

Yeşil Sukuku Piyasa Oyuncularına Kanıtlamak (Tanıtmak) Üzere Gösterge İhraçlar Yapılması:

Güvenilir ve tanınmış kuruluşlarca yapılan stratejik yeşil sukuk ihraçları yeşil sukuk piyasasını başlangıç aşamasından öteye canlandırmak için anahtar rolüne sahiptir. İhraççı kuruluşun tanınmış bir kuruluş olması halinde gösterge ihraçlar yatırımcıları cezbedecek ve onları varlı sınıfları konusunda bilgilendirecektir.

Kalkınma bankaları, belediyeler ve merkezi hükümetler gibi kamu kurumları gösterge ihraçlar yapılması için önemli kuruluşlardır. Bu kuruluşlarca yapılan ihraçlar ise yeşil sukuk piyasasının gelişmesi için stratejik öneme sahiptir. Çeşitli kuruluşlarca yapılaması planlanan gösterge ihraçlar ise yeşil sukuk piyasası için olumlu gelişmeler mahiyetindedir. Nitekim, Müslüman dünyasındaki en büyük kalkınma organizasyonu olan İslam Kalkınma Bankası 2018'de yenilenebilir enerji projelerini finanse etmek adına gösterge niteliğinde 1 milyar 
dolarlık yeşil sukuk ihraç edeceğini duyurmuştur. Amacın ise yeşil sukuk için gösterge oluşturmak olduğu belirtilmiştir (Reuters, 2018). Fazlası:

Kamu Sektörü Desteği: Gösterge Yatırım, Vergisel Teşvikler ve Daha

Kamu sektörünün desteği yeşil sukuk piyasasının canlanması için hayati öneme sahiptir. Kamu sektörü desteğine duyulan ihtiyaç sadece yeşil sukuka has değildir; yeni bir finansal piyasa için, hükümetin piyasanın ilk aşamalarında sağlıklı ve dinamik büyümesini desteklemek için uygun bir ortam yaratmada merkezi bir rolü vardır.

En temel eylemler, düşük mali etkilere sahip olan ve yeni finansal piyasaları desteklemede başarısı kanıtlanmış olan piyasa geliştirme faaliyetleridir. $\mathrm{Bu}$ eylemler arasında standartların geliştirilmesini destekleme, gösterge ihraçlar yapma ve yeşil sukukla finansmana uygun yeşil altyap1 projeleri yapma sayılabilmektedir.

Sermaye piyasasının gelişimini desteklemek amacıyla kanıtlanmış etkisi olan destekleme araçları olmakla birlikte bu araçların kullanımı politika önceliklerine ve ülkenin mali alanına göre farklılaşmaktadır. Bu araçlar arasında, yeşil sukuka stratejik kamu yatırımı, vergisel teşvikler ve kredi değerliğinin arttırılması sayılabilmektedir.

İşbirliği: Yeşil Sukuk Çalışma Grubu:

İyi işleyen bir yeşil sukuk piyasasının temel bileşeni anahtar rolündeki kuruluşlarca varılan işbirliğidir. Finansal sektör oyuncuları çevreci uzmanlarla yeşil enstrümanların hem finansal ve hem de çevrecilik bakımından güçlü olmasını sağlamak amacıyla işbirliğine gitmelidir. The Clean Energy Business Council of the Middle East and North Africa, the Climate Bonds Initiative ve the Gulf Bond and Sukuk Association,işbirliğine giderek piyasa uzmanlığını yeşil sukukun gelişimine kanalize etmek amacıyla Yeşil Sukuk Çalışma Grubu'nu kurmuşlardır.

\section{YEŞIL SUKUKUN GELECEĞİ}

Yeşil sukuk niş bir piyasa olmasının yanında birçok problemlere sahiptir ve gelecekteki başarı şansı problemlerin çözümü yanında enerji arzına, bu arza olan talebe, yatırımcıların farkındalığına ve devlet desteğine bağlıdır. Bu anlamda yeşil sukukun geleceğini belirleyen faktörler Şekil 2'de özet olarak belirtilmiştir.

Şekil 2. Yeşil Sukukun Geleceğini Belirleyen Faktörler

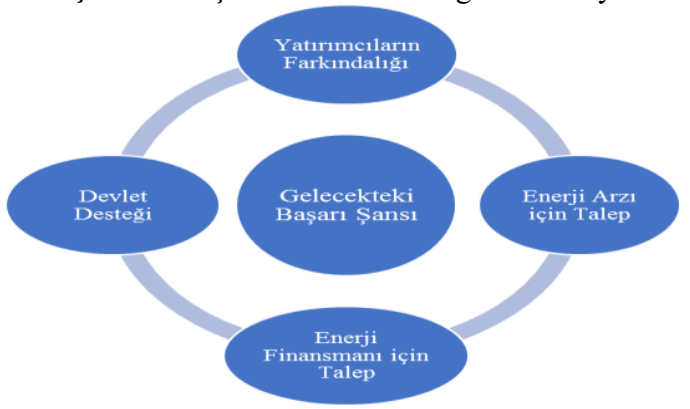

Kaynak: (2016). SRI \& Green Sukuk: Challenges \& Prospects. http://www.mifc.com/index.php?ch=28\&pg=72\&ac=162\&bb=uploadpdf (Erişim Tarihi:05.06.2018). 
Yeşil sukukun gelecekteki başarı şansı aşağıda yer alan birçok faktörce belirlenmektedir (MIFC, 2016:3-4):

1.İlk faktör enerji üretimi (arzı) için oluşacak taleptir. Bilindiği üzere gelecekte nüfus artacağından dolayı temiz enerji ve enerji etkinliği ihtiyacı da artacaktır. Örneğin, Körfez İşbirliği Konseyi Ülkeleri (GCC) nüfusunun 2020'de 2000 yılına göre \%30 artacağı öngörülmektedir. Bu da Körfez bölgesini dünyada en hızlı büyüyen bölgelerden biri haline getirmektedir. Bunun sonucunda ise enerji, su, ulaşım, kentsel gelişim ve altyapı için talebin artacağı kaçınılmaz bir gerçektir. İlave olarak, dünya nüfusunun 1999'da 6 milyardan 2044'te 9 milyara ulaşacağı yani dünya nüfusunda $\% 50$ artış olacağı beklenmektedir.

2. İkinci faktör enerji yatırımları finansmanı için oluşacak taleptir. Nüfusta önemli bir artış beklendiğinden dolayı temiz enerji ve enerji etkinliği yatırımlarında bir artış ve bunun sonucunda da bu yatırımların finansmanında kullanılacak fonlara önemli bir talep olacağı beklenmektedir. Nüfus artışı sonucu oluşacak talebi karşılayabilmek amacıyla iddialı girişimler ve proje planları yapılmaktadır. Örneğin, King Abdullah City for Atomic and Renewable Energy (KA-CARE) 2032'ye değin 54.000 megawattllk yenilenebilir enerji üretmeyi amaçladığına dair beyaz bülten (tanıtım bülteni) yayınlamıştır. Diğer yandan, HSBC, 2010-2020 yılları arasında kümülatif sermaye yatırımlarının yaklaşık 10 trilyon ABD dolarının düşük karbon enerjisine doğru kayacağını tahmin etmiştir. Bir başka tahminde bulunan Uluslararası Enerji Kuruluşu'na göre önümüzdeki 20 yılda iklim değişikliği ile savaşmak için gerekli fon miktarı 10 trilyon doları aşmaktadır (McAughtry, 2015; Saidi, 2012).

3.Sosyal yönden sorumlu yatırımlara olan yatırımc1 ilgisi bir diğer faktördür. Eylül 2014'te 2 trilyon dolarlık varlı̆̆ın yönetiminde olan global yatırımcılar, iklim değişiminin çözümüne yönelik finansman piyasasına artan ilgilerinin (yatırımlarının) olduğunu açıklamışlardır. Barclays 2016'ya kadar yeşil tahvil piyasasında 1.48 milyar dolarlık yatırım yapmayı amaçlamaktadır.

4.Devlet desteği yeşil sukukun geleceğini belirleyecek olan önemli bir faktördür. Nitekim devletlerce çıkarılacak rehberler, standartlar, yapılacak gösterge ihraçlar ve verilecek vergisel teşvikler yeşil sukukun geleceğini belirleyecektir. Devlet desteği hakkında son dönemlerde önemli gelişmeler yaşanmıştır. 2018'de Endonezya dünyada devletçe yapılan ilk sukuk ihracını gerçekleştirmiştir ve bu ihracın diğer yeşil devlet sukuku ihraçları için model olacağı düşünülmektedir. Bu anlamda Malezya'nın ikinci en büyük bankası CIMB Group ise 2018'de yeşil sukuk piyasasına girecek devlet sayısının 5 olacağını öngörmektedir (The Star, 2018). Diğer yandan Sürdürülebilir ve Sorumlu Yatırım (SRI) Sukuku uygulaması altında yer verilen yeşil sukuka yönelik olarak Malezya'da yeşil sukuka yönelik vergisel teşvikler söz konusudur: 2020 vergi yılına değin Malkezya Menkul Kıymet Komisyonu (SC)'ce onaylanan veya da SC'de ihraç edilen Sürdürülebilir ve Sorumlu Yatırım (SRI) Sukuku ihraçlarının maliyeti vergiden indirilebilecektir. Vergi indirimine hak kazanmak için yeşil projeler yoluyla SRI sukuk uygulamasından yararlanan ihraççı, SRI sukuktan elde edilen fonların doğal kaynaklar, yenilenebilir enerji ve/veya enerji 
etkinliği sektörlerinde yer alan SRI projelerinde kullanıldığını kanıtlamalıdır. Yeşil sukuk ihracından önce uluslararası uygulamalara uygun olarak ihraççı projenin uygunluğunu değerlendirecek bir uzman atamalıdır (Securities Commisssion Malaysia, 2017).

\section{POTANSIYYELI}
IX. TÜRKIYYE'DE
YEŞIL
SUKUKUN
UYGULANMA

Türkiye'de büyüyen ekonomi ve nüfus artışı nedeniyle enerji ve doğal kaynaklara olan talep artmaktadır. Son yıllarda Türkiye, OECD ülkeleri arasında enerji talebinde en hılı büyümeyi göstermiştir. Ayrıca Uluslararası Enerji Ajansı (IEA)'nın tahminlerine göre, önümüzdeki on yılda enerji kullanımının iki katına çıkması beklenmektedir. Ayrıca, Enerji Bakanlığı'nın tahminleri bu eğilimin orta ve uzun vadede devam edeceğini teyit etmektedir (Invest in Turkey, 2018a).

Türkiye, yenilenebilir enerji alanında önemli bir kaynak potansiyeli de taşımaktadır (Karagöl ve Kavaz, 2017). Bu potansiyelin bir gereği olarak Türkiye'de atılan adımlar yenilenebilir enerjinin önümüzdeki yıllarda artacağını işaret etmektedir. Nitekim, Türkiye Cumhuriyeti'nin kuruluşunun 100. yilının kutlanacağ 2023 yılına yönelik vizyonu dahilinde enerji üretiminde yenilenebilir enerji kaynakları payının \%30'a yükseltilmesi hedeflenmektedir. Ayrıca, 2016 yılında Yenilenebilir Enerji Kaynak Alanı (YEKA) modelinin uygulanmaya koyulması ve bu model ile, Türkiye'nin tarihindeki en büyük güneş enerjisi ihalesini 20 Mart 2017 tarihinde gerçekleştirilmiş olması da Türkiye'de yenilenebilir enerjiye yönelik ilgi ve yatırım potansiyelini gözler önüne sermektedir (Invest in Turkey, 2018b). Diğer yandan, PWC (2017:6)'ya göre Türkiye'nin 2023 'e değin 39 milyar dolarlık yenilenebilir enerji yatırımı yapması beklenmektedir.

Türkiye'nin önümüzdeki yıllarda yenilenebilir enerji alanında atacağı güçlü adımlar, Türkiye'de yeşil sukukun uygulanabilirliği için önemli bir potansiyel sunmaktadır. Ancak hemen belirtmek gerekir ki Türkiye'de yeşil sukuka yönelik düzenlemeler bir yana sukuka ilişkin düzenlemeler de bir hayli yetersizdir. Nitekim Türkiye'de sadece beş tür sukuk (sahipliğe dayalı, ortaklığa dayalı gibi) ihracını mümkün kılan yasal düzenlemeler var iken vergisel düzenlemeler sadece ijara sukuka (sahipliğe dayalı sukuk) yani kira sertifikasına yöneliktir. Yeşil sukuka ilişkin ise herhangi bir düzenleme veya niyet ortada yoktur.

Dünyada ihracı hızla artan yeşil tahvillerden sonra yeşil sukuk ihraçları da henüz yeni olmasına rağmen artarak devam etmektedir. Türkiye'nin de yeşil sukuk piyasasından payını alması ve yerel sukuk piyasasını gerek ülkede bulunan kuruluş ve yönetimlerce ve gerekse de ülke dışından çekeceği sukuk ihraçları ile geliştirmesi için yeşil sukuka ilişkin yasal ve vergisel düzenlemelere gitmesi gerekmektedir. Bu düzenleme ve teşvikler ise Malezya gibi ülkelerce verilen teşvikler değerince olmalı, böylece Türkiye uluslararası piyasada sukuk ihraç ve yatırımları çekebilmelidir. Anca belirtmek gerekir ki, yasal ve vergisel düzenlemeler ilk önce genel anlamda sukuk için düzenlenmeli ve örneğin diğer ülkelerle rekabet edecek düzeyde olmayan stopaj oranları indirilmelidir. Genel 
anlamda sukuka ilişkin yasal ve vergisel düzenlemelerin ardından yeşil sukuka ilişkin yasal ve vergisel düzenlemeler başvurulmalı ve henüz gelişen yeşil sukuk fırsatı Türkiye tarafindan kaçırılmamalıdır.

Yeşil sukukun Türkiye tarafından ihraç edilmesinin hiç şüphesiz birçok faydasından bahsetmek mümkündür. İlk olarak yeşil sukuk çok daha geniş bir yatırımcı tabanına hitap etmekte ve bu nedenle yatırımcı tabanında çeşitlendirme imkânı sunmaktadır. Bu gelişme ise hiç şüphesiz borç kırılganlığı gibi borçlanma problemleriyle başa çıkabilmek adına Türkiye'nin elini güçlendirecektir. İkinci olarak yeşil sukuk rekabetçi fiyatlara sahiptir. Genel olarak sukuka ilişkin standartlaşma ve problemleri azaltma çabaları sukuku daha rekabetçi ve bilinir hale getirirken yeşil sukuk hiç şüphesiz bu gelişmelerden faydalanarak daha rekabetçi oranlara sahip olabilecektir. $\mathrm{Bu}$ durum ise ülkelerin borçlanmada maliyet minimizasyonu hedefine hizmet edebilecektir. Üçüncü olarak, yeşil sukuk ile yenilenebilir enerji yatırımları hızlı biçimde yapılabilecektir ki Türkiye'nin asıl hedeflerinden bir tanesi de budur. Son söz olarak yeşil sukukun Türkiye'ye birçok ekonomik faydasından bahsetmek mümkündür. $\mathrm{Bu}$ açıdan Türkiye'nin yeşil sukuk için gerekli yasal ve vergisel düzenlemeleri bir an önce gerçekleştirmesi bir yandan ülkede yeşil yatırımları daha hızlı arttırabilirken diğer yandan borç yönetimini de kuvvetlendirecektir.

\section{SONUÇ}

Yeşil sukuk henüz yeni gelişen bir ürün olarak potansiyelini gerçekleştirebilmiş bir ürün değildir. Ancak son y1llarda gerek özel sektörden gerek uluslararası kuruluşlardan ve gerekse de devletlerden sukuk ihraçları ya da ihraç edileceğine dair niyet gelmeye başlamıştır. Yeşil sukuk birçok avantajının yanında finansman kaynaklarında çeşitlendirmeye önemli biçimde hizmet ederken diğer yandan yenilenebilir enerji yatırımlarının finansmanında da önemli bir görev üstlenmektedir. Bu anlamda birçok avantaja sahip olan yeşil sukuk firsatı Türkiye tarafindan da değerlendirilmelidir. Nitekim Türkiye, önümüzdeki yıllarda yenilenebilir enerji gibi çevresel alanlara yatırım yapma potansiyeli oldukça yüksek olan bir ülkedir ve bu anlamda Türkiye'nin yeşil sukuktan yararlanma yolları oldukça açıktır. Ancak belirtmek gerekir ki Türkiye'de sukuka ilişkin gerek yasal ve gerekse de vergisel düzenlemeler yeterli derecede değildir. Türkiye'de ancak beş çeşit sukuk ihracına imkân veren yasal düzenlemeler var iken vergisel düzenlemeler ancak ijara sukuka yani kira sertifikasına yöneliktir. Türkiye'de yeşil sukuka ilişkin düzenleme yapılmadan önce sukuk piyasasında var olan bu ve benzeri problemler çözülmelidir. Daha sonra ise yeşil sukuka ilişkin yasal düzenlemeler oluşturulmalı bu düzenlemeler vergisel teşvikler ile denetlenmelidir.

Çevresel yatırımların gelecekte ülkelerin en önemli yatırım alanları olacağına dair birçok kuruluş önemli tahminlerde bulunmuşlardır. Türkiye çevresel yatırımlarda önemli bir potansiyele sahip olan bir ülke olarak henüz yeni gelişen yeşil sukuk firsatını kaçırmamalı ve uluslararası nitelikteki yasal ve vergisel düzenlemeler ile yeşil sukuk merkezi olmak için önemli adımlar 
atmalıdır. Ancak bu sayede geleceğin sürdürülebilir yatırımı olan çevresel yatırımlardan kendine düşen payı alabilecektir

\section{KAYNAKÇA}

Abdul Aziz, A. H. (2017a). Green Bond/Sukuk. https://www.rbf.gov.fj/getattachment/LeftMenu/Financial-Inclusion/Events/Workshop-on-Sustainable-Finance-Initiatives/Session4-Green-Bonds-by-Ahmad-Hafiz-Abdul-Aziz-World-Bank-Group.pdf?lang=en-US (Erișim Tarihi:05.06.2018).

Abdul Aziz, A. H. (2017b). Green Sukuk/ Bond for Sustainable Development. http://www.iifm.net/sites/default/files/Session\%204\%20-

$\% 20$ Green $\% 20$ Sukuk\%2C\%20Financing\%20the\%20Future\%20-

\%20Ahmad\%20Hafiz\%20\%28World\%20Bank\%29.pdf (Erişim Tarihi:05.06.2018).

Al Natoor, B. (2017). Why Green Sukuk Copuld be a Growth Drbver for Islamic Finance. https://medium.com/fitch-blog/why-green-sukuk-could-be-a-growth-driver-for-islamicfinance-d6881f592f5c (Erişim Tarihi:05.06.2018).

Alam, N., Duygun, M. and Turk Ariss, R. (2016). Green Sukuk: An Innovation in Islamic Capital Markets ( Edited by Andre Dorsman, Özgür Arslan-Ayaydın and Mehmet Baha Karan). Energy and Finance Sustainability in the Energy Industry (First Edition). Switzerland: Springer International Publishing,. 167-185.

Ali, M. M. ve Abdullah, S. M. (2017). Green Sukuk: Present State and Future Outlook. http://www.iais.org.my/e/attach/2017/20NOV2017_GreenTech/presentations/Session3_Sp eaker3_MahbubiAli.pdf(Erişim Tarihi:05.06.2018).

Chew, E. (2014). Malaysia Green Sukuk Gets Khazanah Debut Boost: Islamic Finance. https://www.bloomberg.com/news/articles/2014-11-25/malaysia-green-sukuk-getskhazanah-debut-boost-islamic-finance (Erişim Tarihi:06.06.2018).

Climate Bonds (2017). Green Sukuk. https://www.climatebonds.net/projects/facilitation/greensukuk (Erişim Tarihi:07.06.2018).

Dunkley, E. (2018). Indonesia Issues World's First Green Sukuk Bond. https://www.ft.com/content/e38ea51c-184c-11e8-9376-4a6390addb44 (Erişim Tarihi:03.06.2018).

G20 Green Finance Study Group (2016). Green Bonds: Country Experiences, Barriers and Options. http://unepinquiry.org/wpcontent/uploads/2016/09/6_Green_Bonds_Country_Experiences_Barriers_and_Options.p df (Erişim Tarihi:05.06.2018).

Hirtenstein, A. (2015). Islamic Bank May Support Green Sukuk for Renewables Projects. http://www.bloomberg.com/news/articles/2015-11-03/islamic-bank-may-support-greensukuk-for-clean-energy-project (Erişim Tarihi:08.06.2018).

Invest in Turkey (2018a). Turkey's Renewable Energy Market and Instrument Opportunities. http://www.invest.gov.tr/en-

US/infocenter/publications/Documents/RENEWABLES.ENERGY.INDUSTRY.pdf (Erişim Tarihi:25.02.2019).

Invest in Turkey (2018b). Enerji ve Yenilenebilir Kaynaklar. http://www.invest.gov.tr/trTR/sectors/Pages/Energy.aspx (Erişim Tarihi:25.02.2019).

Irvine, L. Grifferty, M. and Cowman, A. (2014). Green Sukuk: The Race to Be First. https://www.islamicfinancenews.com/green-sukuk-the-race-to-be-first.html (Erişim Tarihi:07.06.2018).

Karagöl, E. T. ve Kavaz, İ. (2017). Dünyada ve Türkiye'de Yenilenebilir Enerji. https://setav.org/assets/uploads/2017/04/YenilenebilirEnerji.pdf (Erişim Tarihi:25.02.2019).

Khazzam, E. R. (2015). How Islamic Finance Facilitates Green Investment. https://www.ifac.org/global-knowledge-gateway/islamic-finance/discussion/how-islamicfinance-facilitates-green-investment (Erişim Tarihi:01.06.2018). 
Kidney, S. (2015). Green Sukuk: Hot Topic at the World Islamic Economic Forum-Malaysia. https://www.climatebonds.net/2015/11/green-sukuk-hot-topic-world-islamic-economicforum-malaysia (Erişim Tarihi:10.06.2018).

McAughtry, L. (2015). The Grass is Always Greener? Environmental Sukuk Take The Stage. http://islamicfinancenews.com/newsletter-issue/volume12issue11

(Erişim Tarihi:02.06.2018).

MIFC (2016). SRI \& Green Sukuk: Challenges \& Prospects. http://www.mifc.com/index.php?ch=28\&pg=72\&ac=162\&bb=uploadpdf (Erişim Tarihi:05.06.2018).

Mohammed, N. (2014). The Sukuk Financing Model for Green Projects. https://www.sukuk.com/article/sukuk-financing-model-green-projects-2202/ (Erişim Tarihi:08.06.2018).

PWC (2016). Developing Renewable Energy Projects A Guide to Achieving Success in MENA. Fourth Edition. https://www.pwc.com/m1/en/publications/documents/eversheds-pwcdeveloping-renewable-energy-projects-4th-edition.pdf (Erişim Tarihi:08.06.2018).

PWC (2017). Capital Projects and Infrastructure Spending in Turkey January 2017 Outlook to 2023. https: //www.pwc.com.tr/tr/advisory/capital-project-and-infrastructure-spendingin-turkeypwc.pdf (Erişim Tarihi: 27.08.2017).

Rado, G. (2018). Jan Market Blog: Strong start to 2018: GBs from Asia \& Norway: Green Sukuk: Sovereigns \& Certified Bonds to Start the Year. https://www.climatebonds.net/2018/02/jan-market-blog-strong-start-2018-gbs-asianorway-green-sukuk-sovereigns-certified-bonds (Erişim Tarihi: 27.08.2017).

Reuters (2018). Islamic Development Bank Aims to Sell \$1 bln Green Sukuk in 2018. https://www.reuters.com/article/sukuk-issue-idb/islamic-development-bank-aims-to-sell1-bln-green-sukuk-in-2018-idUSL5N1QN4KP (Erişim Tarihi: 30.08.2017).

Securities Commission Malaysia (2017). Malaysia's First Green Sukuk under SC's Sustainable Responsible Investment Sukuk https://www.sc.com.my/post_archive/malaysias-first-green-sukuk-under-scs-sustainableresponsible-investment-sukuk-framework/ (Erişim Tarihi: 05.06.2017).

The Star (2018, 6 Şubat). CIMB expects sovereigns to 1ssue green 1slamic bonds in 2018. https://www.thestar.com.my/business/business-news/2018/02/06/cimb-expectssovereigns-to-issue-green-islamic-bonds-in-2018/ (Erişim Tarihi: 27.08.2017).

Vizcaino, B. (2018). Green, Islamic Investors Find Common Ground with Indonesian Sukuk. https://www.reuters.com/article/indonesia-sukuk-esg/green-islamic-investors-findcommon-ground-with-indonesian-sukuk-idUSL8N1QK0SE (Erişim Tarihi: 28.08.2017).

World Bank (2017). Green http://www.worldbank.org/en/news/infographic/2017/09/19/malaysia-green-sukuk (Erişim Tarihi: 25.08.2017).

Zain, N. R. M. Abideen, A. and Ali, E. R. A. E. (2017). Innovations of Sukuk in Global Finance Market: Some Considerations. The 5th Asean International Conference on Islamic Finance, 13-14 December 2017, Jerudong, Brunei Darussalam. Brunei Darussalam. UNISSA Press

\section{SUMMARY}

In recent years, green infrastructure investments have increased steadily. Parallel to that, green financing methods have also begun to vary. In this sense, the first green bonds were issued in 2008 to finance green infrastructure projects. Research and efforts on green sukuk, which have benefited from the experience of green bonds, have increased rapidly in the last decade. As a result of this, the first green sukuk was issued in Malaysia by Tadau Energy in 2017.

The green sukuk market is a niche market that is still in development. Hence, there are some basic problems about the development of green sukuk. However, many countries have made legal and tax regulations to improve the 
green sukuk market. The main reason for this is that the countries want to benefit from the benefits of green sukuk. In this regard, green sukuk helps countries to diversify financing resources and fund green investments.

In Turkey, there are no legal regulations on green sukuk yet. Hovewer, in Turkey green sukuk has a great potential to fund green investments. Because, Turkey is expected to invest 39 billion dollars in renewable energy until 2023. However, legal and tax regulations for sukuk in Turkey is weak and should be reconsidered. Then, similarly to other countries, Turkey must make legal arrangements for the green sukuk and should provide tax advantages. In this way, Turkey will develop the sukuk market achieve its goal of becoming an Islamic financial center. 